\title{
A New Ship-Targeting Model for Ship Supervision Based on
}

\section{AHP-DEA Method}

\author{
Aijuan Chen ${ }^{1, a}$, Pengjun Zheng ${ }^{1, b}$ \\ ${ }^{1}$ Ningbo University, Faculty of Maritime and Transportation, Ningbo 315211, China \\ ${ }^{2}$ Ningbo University, Faculty of Maritime and Transportation, Ningbo 315211, China \\ a1021109855@qq.com, ${ }^{b}$ zhengpengjun@nbu.edu.cn
}

Key words: ship site supervision; index system; ship-targeting model; AHP-DEA

\begin{abstract}
The paper analyzes the deficiencies of the existing integration methods of AHP and DEA, improves the integration method and establishes a ship- targeting model for ship site supervision based on AHP-DEA method. This paper filters the indicators which covered the main factors that affect the safety of ship by analytic hierarchy process, and establishes the evaluation index system. The paper selects 22 vessels as the experimental sample, realizes the sorting and classification of ship site supervision and ship's risk degree through case analysis. The results are compared with those which are based on fuzzy comprehensive evaluation, China's new ship-targeting regulation of flag State control and Tokyo Memorandum new inspection regulation in order to prove that the classification of AHP-DEA is more reasonable. Meanwhile, compared with FCE method, AHP-DEA is more objective and less accidental. The method has the advantages of simple steps and convenient calculation, and has certain practical values for vessel supervision.
\end{abstract}

\section{Introduction}

"Vessel Supervision" refers to safety management and supervision and inspection activities of the maritime management agencies upon the ship, the crew and its related activities to see whether they are in line with laws and regulations, administrative rules and regulations, or China's conclusion or accession of the relevant international conventions and our country's accession to the provisions of the regional cooperation organizations. The "vessels" mentioned above refer to Chinese vessels and water facilities (hereinafter referred to as " vessels ") as well as foreign vessels that navigate, moor and operate in the waters under our jurisdiction.[1] Under the situation that the government deeply promotes the transformation of functions and simplifies power and decentralization, the cancellation of the ship's visa will affect the current methods and effects of general inspections carried out by the maritime administrations carrying out general inspections on the seaworthiness of ships, and weakened inspections on the seaworthiness of ships. As a result, a new round of adjustment in maritime regulatory mode will take place, the allocation of maritime regulatory resources will be further focused and rationalized. Due to the limited resources possessed by on-site law enforcement, ship supervision and precision problems urgently need to be solved, a ship- targeting model for ship site supervision need to be established.

The current model of the selection of vessels simply divides the vessels into three types of vessels and can not further differentiate the priority supervision orders for similar vessels. In fact, shiptargeting is selecting the corresponding priority inspection of the ship. If the risk degree of the ship can 
be sorted, then it can distinguish between determine the priorities of order of priority supervision and further optimize the allocation of marine regulatory resources.

At present, the domestic and foreign research mainly adopts the evaluation method which is called the subjective judgment by the decision maker (hereinafter referred to as subjective evaluation method) and the evaluation method which is based on the objective data (hereinafter referred to as objective evaluation method) to improve ship- targeting model.[2-4] Subjective evaluation method mainly includes AHP and fuzzy comprehensive evaluation method and so on. It reflects the preferences of policy makers, but to some extent, it is too reliedepends too muchent on the decision maker's subjective judgment. The objective evaluation method [5-7] mainly includes BP neural network method, support vector machine theory, Bayesian network method and comprehensive safety assessment method. To a certain extent, the model of the selected vessel has been improved and has its own advantages, but it can not reflect the preferences of policymakers and it's possible that the result does not accord with the actual situation.

Based on this, this article finds a method to reflect the subjective judgments of decision makers as well as objective data,. namely, That is the method of combining Analytic Hierarchy Process (AHP) and Data Envelopment Analysis (DEA). Many scholars at home and abroad have effectively integrated these two methods and applied them in multi-objective evaluation. Considering that it can not only reflect the preferences of policy makers, reflect the actual situation, but also avoid not unduly relying on the subjective judgments of policymakers. A method of effective integration of AHP and DEA is proposed and applied for the first time to vessel supervision. A ship- targeting model based on AHP-DEA is established, and the validity and superiority of the model are verified, through case analysis.

\section{Methodology}

Analytic hierarchy process [8] is a multi-objective decision analysis method combining qualitative and quantitative analysis proposed by Saaty in 1977. Data envelopment analysis method [9] is based on "relative efficiency" put forward by American operations research scientists. It is a systematic analysis method to evaluate the relative effectiveness of Decision Making Units (DMU) based on multi-index input and multi-index outputs. There are four main modes of integrating AHP with DEA. The first is to use the AHP as a constrained cone DEA method [10]. The integrated approach requires AHP method to determine the weight of all the indicators. When there are many indicators, it will bring great difficulties to the subjective judgment and also easily lead to inconsistency of the judgment matrix. The second is to divide each two decision-making unit into a group and construct a judging matrix for comparing two-by-two efficiency values. It uses AHP to calculate its eigenvectors, and sorts according to eigenvectors. This integrated approach is suitable for models with fewer indicators. If there are more indexes, the existence of two decision-making unit could easily lead to most efficiency value to be 1 , resulting in the reliability of the results being not high; The third is to calculate the weight evaluation value of AHP $w$ and the valid value of DEA $\theta$, then introduce the coefficient of preference $\alpha$, and use the formula $A=\alpha w+(1-\alpha) \theta$ to get the comprehensive evaluation value [12]. This kind of integration is the same as the first one, which needs to subjectively judge the weight of all the indexes and does not apply to the model with more indexes; The fourth is to make use of AHP method to calculate the weight of various factors $w_{i}$. And then use DEA method to calculate $\theta_{i j}$, which is the performance various of decision-making unit of various indicators. And the last step is to use the 
formula $\theta_{j}=\sum_{i=1}^{\alpha} \theta_{i j} w_{i}$ to calculate comprehensive effective value $\theta_{j}$ [13-15]. Vessel supervision index system has two levels of indicators, the first-level indicators (various indicators) is a small number. It's easy to make subjective judgments and uniformly accepted weights can be determined by expert evaluation. However, there are too many secondary indicators. It's unable to determine uniformly accepted weights. This problem can be solved by obtaining the optimal weight of the second-level index through the DEA method. To sum up, only the fourth integration method is more suitable for the selected vessel model because the vessel monitoring selection involves more indicators. However, the weighted summation of $\theta_{i j}$ is based on the assumption that the first-level indicators have the same impact on the ship's safety. But $\sum_{j=1}^{n} \theta_{i j}$ is unequal, which means that the impact of the first-level indicators on the ship's safety is different. So there is a conflict here, and it needs to be improved.

\section{Model description}

Evaluation Indicators. Taking into account that the complexity of the factors that affect shiptargeting, the article is based on the principles of hierarchy, importance and systematicness. It determines the weight of evaluation index by Analytic Hierarchy Process and Expert Consultation Method. Thus, the evaluation index is determined. There are 16 experts, mainly including masters, ship owners, managers of Maritime Administration, personnel of ship supervision department, professors and other personnel. The steps of target selection based on AHP are as follows: (1) Establish a hierarchy. Drawing on the experience of the regional memoranda and flag State supervisors with the actual situation of vessel supervision, the evaluation index and evaluation factor are initially selected and a preliminary index system established. The target level is A, that is, the degree of risk of the ship. The first level of indicators is B, which includes indicators on ships, indicators on shipping companies, seamen's indicators, classification societies on indicators, flag states and indicators of accredited organizations. The two level indicator layer is C, and there are 19 evaluation factors.(2) Construct judgment matrix. (3)Calculate the weight of level B index and consistency test. If $C R=0.0749<0.1$, it indicates that the consistency requirement is satisfied. The B-level indicators have the following weightings in terms of ship (0.424), shipping company (0.255), crew (0.150), flag state (0.087), recognized organization (0.052) and classification society (0.031). It can be seen that the ship's indicators have the greatest impact on the ship's supervision and selection of vessels. The shipping companies play an active role in the scientific and effective management of ships and crew and in enhancing the safety of ships. As a result, the indicators of the shipping company are the factors that should be seriously considered in the supervision of the ship. Statistics show that about $80 \%$ of all shipwrecks are related to human factors. So the crew's indicators are also important. The other three aspects of the weight of the index are relatively small. Therefore, based on the above analysis results and the research on the model of ship selection at home and abroad, the B-tier evaluation indicators for the final screening are indicators of the ship, the shipping company and the crew. Then build the index system, as shown in Table 1. 
Table1 the evaluation index system of a ship- targeting for ship site supervision

\begin{tabular}{|c|c|c|}
\hline Target level & Guidelines layer & Indicator layer \\
\hline \multirow{14}{*}{$\begin{array}{l}\text { Ship risk } \\
\text { level }\end{array}$} & \multirow{6}{*}{$\begin{array}{l}\text { Ship aspect } \\
\text { indicators }\end{array}$} & $\begin{array}{l}\text { The number of ship accidents in which ships assumed the } \\
\text { primary responsibility and above in the past } 36 \text { months }\end{array}$ \\
\hline & & The number of administrative penalties in the past 36 months \\
\hline & & $\begin{array}{l}\text { The recorded number of defects that exceeded } 4 \text { in the past } \\
\qquad 36 \text { months }\end{array}$ \\
\hline & & The number of ships stranded in recent three years \\
\hline & & Whether rated as safe and honest ship \\
\hline & & Whether listed as the key tracking ship \\
\hline & \multirow{5}{*}{$\begin{array}{l}\text { shipping } \\
\text { company } \\
\text { indicators }\end{array}$} & Retention index \\
\hline & & The average number of defects \\
\hline & & $\begin{array}{c}\text { The number of company's ships that have experienced a major } \\
\text { maritime accident and above in the past } 36 \text { months }\end{array}$ \\
\hline & & $\begin{array}{c}\text { The number of administrative penalties accepted by } \\
\text { company's ships in the past } 36 \text { months }\end{array}$ \\
\hline & & Whether rated as safe and honest shipping company \\
\hline & \multirow{3}{*}{ Crew indicators } & Whether the captain was rated as safe and honest captain \\
\hline & & The average number of points deducted on board \\
\hline & & Crew replacement frequency \\
\hline
\end{tabular}

The indicator system consists of two levels of indicators, the first level indicators include ships, shipping companies and crew, There are 15 indicators of secondary indicators, covering the main factors affecting the safety of the ship. Among them, the four indicators, which are whether it is rated as safe and honest ship, whether it is the key tracking ship type, whether it is rated as safe and honest shipping company and whether it is rated as safety and integrity of the ship captain, reflect the ship's safety and are thus set as output targets. The other eleven indicators are the reasons that affect the safety of the ship and are set as the input indicator.

AHP-DEA model. Assuming that $n$ ships in the port are to be evaluated, the establishment of the index system has two levels of indicators. Among them, there are $\alpha$ the first level indicators, namely, $\alpha$-level indicators, and there are $\beta_{i}$ second-level indicators including $m_{i}$ input indicators and $s_{i}$ output indicators. $x_{l j}, y_{r j}$ is the index value of the lth input index and the rth output index of the ith index of the $j$ th ship; $v_{l}, u_{r}$ is the weight variable of the input indicator and the output indicator; Under the assumption that the corresponding production sets satisfy the triviality, convexity, taper, inefficiency and minimum, to evaluate the efficiency of the decision making unit $D M U_{i j}$ of the ith indicator of the $j t h$ ship, to be constrained by the efficiency index of all decision-making units, and then to create a linear programming model, the results are Equations (refer with: Eq. 1, Eq. 2, Eq. 3)

$$
\begin{aligned}
& \min \left[\theta_{i j}-\varepsilon\left(\hat{e}^{T} S_{r}^{-}+e^{T} S_{l}^{+}\right)\right], j=1,2 \ldots n \\
& \hat{e}^{T}=(11 \ldots 1) \in E_{m_{i}}, \quad \mathrm{e}^{\mathrm{T}}=(11 \ldots 1) \in \mathrm{E}_{\mathrm{s}_{\mathrm{i}}}
\end{aligned}
$$




$$
\text { S.t. }\left\{\begin{array}{c}
\sum_{j=1}^{n} \mathrm{v}_{l} x_{l j}+S_{l}^{+}=\theta_{i j} x_{l 0} \\
\sum_{j=1}^{n} u_{r} y_{r j}-S_{r}^{-}=y_{r 0} \\
v_{l} \geq 0, \quad u_{r} \geq 0 \\
S_{r}^{-} \geq 0, \quad S_{l}^{+} \geq 0 \\
l=1,2 \ldots m_{i}, \quad r=1,2 \ldots s_{i}
\end{array}\right.
$$

In the formula, $S_{r}^{-}$is the relaxation variables; $S_{l}^{+}$is the remaining variables; $\varepsilon$ is an infinitesimal number of non-Archimedes; $x_{l 0}$ and $y_{r 0}$ are respectively the $l$ th input and the $r t h$ output index of the $i$ th index of a ship being evaluated; $\theta_{i j}$ is the relative effective value of the $i t h$ indicator of the $j$ th ship.

The value of $\theta_{i j}$ indicates the degree of influence of the second-level indicators of a certain vessel on the safety of the vessel. If $\theta_{i j}=1$ and $S_{r}^{-}=S_{l}^{+}=0$, the second-level indicators of the ship are valid for DEA, indicating that the second-level indicators of the ship's impact on the safety of the ship just fall on the frontier of effective production. All the ships under evaluation under the second-level indicator have the highest safety relative validity and safest. If $\theta_{i j}<1$, the second-level target of the ship is non-DEA effective, indicating that the second-level indicators of the ship's impact on the safety of the ship within the effective production frontier breadth and has not reached the safest state. Among all ships evaluated, $\theta_{i j}$ values are between 0 and 1 . The larger the value, the safer and higher the relative validity of the ship's secondary indicators to the ship's safety, and vice versa.

To get the safety ranking for the jth ship considering all the indicators, it's necessary to calculate $\theta_{j}$. Aiming at the problem that $\sum_{j=1}^{n} \theta_{i j}$ is not equal, that is, not satisfied with the assumption that the first level indicators have the same effect on ship safety, the improved scheme is proposed in this paper, which is to normalize $\theta_{i j}$, that is $\overline{\theta_{i j}}=\frac{\theta_{i j}}{\sum_{j=1}^{n} \theta_{i j}}$. Here $\sum_{j=1}^{n} \overline{\theta_{i j}}=1$ satisfies the assumed condition. $\overline{\theta_{i j}}$ can represent the relative size of the secondary indicators on the degree of impact on the ship's safety. And then according to the formula $\theta_{j}=\sum_{i=1}^{\alpha} \overline{\theta_{i j}} w_{i}$, the relative effective value of the $j t h$ ship safety $\theta_{j}$ can be calculated, which represent the degree of safety of the $j t h$ ship. That is, the smaller $\theta_{j}$, the higher the risk of the ship, the higher the priority of the ship's supervision.

Among them, the weight of an indicator $w_{i}$ is:

$$
w_{i}=\frac{\sqrt[\alpha]{\prod_{\rho=1}^{\alpha} b_{i \rho}}}{\sum_{\rho=1}^{\alpha} \sqrt[\alpha]{\prod_{\rho=1}^{\alpha} b_{i \rho}}}
$$

In the formula, $b_{i \rho}$ is the relative importance quantification value of the first level indicators. $w=\left(w_{1}, w_{2}, \cdots w_{\alpha}\right)^{T}$ is the eigenvector of the judgment matrix. And the maximum eigenvalue $\lambda_{\max }$ of the first-level indicator judgment matrix $A$ is 


$$
\lambda_{\max }=\frac{1}{\alpha} \sum_{i=1}^{\alpha} \frac{(A w)_{i}}{w_{i}}
$$

The consistency check needs to be done according to the formula $C I=\frac{\lambda_{\max }-n}{n-1}$. If $\frac{C I}{C R}<0.1$, then the result is in agreement, otherwise the judgment matrix needs to be readjusted.

\section{Case Study}

This article selects 22 ships as the experimental sample. Through the visit to the maritime sector to collect relevant information, visiting the ship management system dynamic 2.0 / integrated business systems, ship registration system, crew management system, two databases, business organizations, query functions, the ship related index value data are retrieved. By consulting the relevant literature and soliciting opinions of 16 shipping experts, the judgment matrix of the first-level index is obtained and the weight of the first-level index $w_{i}$ is calculated as shown in Table 2, which is verified to meet the consistency requirement.

Table2 Primary index weight

\begin{tabular}{|c|c|c|c|}
\hline index & $w_{i}$ & $\lambda_{\max }$ & $\frac{C I}{C R}$ \\
\hline Ship & 0.615 & \multirow{3}{*}{3.074} & \multirow{3}{*}{$0.071<0.1$} \\
\hline Shipping company & 0.268 & & \\
\hline crew & 0.117 & & \\
\hline
\end{tabular}

On the basis of known $w_{i}$ and each index value, software DEAP2.1 is used as tool, $\mathrm{C}^{2} \mathrm{R}$ model is used to calculate the relative effective value $\theta_{i j}$ of the ith index of the $j$ th ship, and $w_{i}$ is combined to obtain the relative effective value $\theta_{j}$ of the $j$ th ship. According to the magnitude of $\theta_{j}$, the ship risk degree is ranked, and the result is shown in Table 3. And according to "twenty-eight law", the ship is divided into high-risk, medium-risk, low-risk ships as shown in Table 3. In order to verify the effectiveness and superiority of this method, this paper evaluates the ships using the fuzzy comprehensive evaluation (FCE), the new selection regime of China's flag state inspection check (FSC) and the Tokyo memo new inspection regime (NIR). Comparison of ship evaluation results based on three different methods are shown in Table 3: 
Table3 Comparison of ship evaluation results

\begin{tabular}{|c|c|c|c|c|c|c|}
\hline Ship & \multicolumn{3}{|c|}{ AHP-DEA } & \multirow{2}{*}{$\begin{array}{c}\text { FCE } \\
\text { Ship } \\
\text { classification }\end{array}$} & \multirow{2}{*}{$\begin{array}{c}\text { FSC } \\
\text { Ship } \\
\text { classification }\end{array}$} & \multirow{2}{*}{$\begin{array}{c}\text { NIR } \\
\text { Ship } \\
\text { classification }\end{array}$} \\
\hline & $\theta_{\mathrm{j}}$ & sorting & $\begin{array}{c}\text { Ship } \\
\text { classification }\end{array}$ & & & \\
\hline 1 & 0.003838 & 1 & high & high & high & high \\
\hline 2 & 0.157208 & 22 & low & low & low & low \\
\hline 3 & 0.068092 & 17 & medium & medium & medium & low \\
\hline 4 & 0.062256 & 14 & medium & medium & medium & medium \\
\hline 5 & 0.008788 & 7 & medium & high & medium & medium \\
\hline 6 & 0.050026 & 13 & medium & medium & medium & medium \\
\hline 7 & 0.005863 & 5 & high & high & high & high \\
\hline 8 & 0.02986 & 12 & medium & medium & medium & medium \\
\hline 9 & 0.065832 & 16 & medium & medium & medium & medium \\
\hline 10 & 0.005553 & 4 & high & high & high & high \\
\hline 11 & 0.004591 & 3 & high & high & high & high \\
\hline 12 & 0.117646 & 21 & low & low & medium & low \\
\hline 13 & 0.01055 & 9 & medium & medium & medium & medium \\
\hline 14 & 0.065557 & 15 & medium & medium & medium & low \\
\hline 15 & 0.007743 & 6 & high & high & medium & high \\
\hline 16 & 0.115008 & 20 & low & low & low & low \\
\hline 17 & 0.024872 & 11 & medium & medium & medium & medium \\
\hline 18 & 0.084832 & 18 & medium & low & medium & medium \\
\hline 19 & 0.010868 & 10 & medium & medium & medium & medium \\
\hline 20 & 0.087545 & 19 & medium & low & medium & medium \\
\hline 21 & 0.004106 & 2 & high & high & high & high \\
\hline 22 & 0.009364 & 8 & medium & medium & medium & medium \\
\hline
\end{tabular}

By comparing the results of the AHP-DEA and FCE methods, we can see that the results of the 5th, 18th and 20th ships are inconsistent. The 18th ship was named a safe and honest ship and has not been detained within three years, the shipping company is a safe and honest shipping company, which should belong to a low-risk ship, The 20th ship was named safety integrity ship, the shipping company is a safe and honest shipping company and the captain is a safe and honest captain, should belong to low-risk ships, It can be shown that the classification of AHP-DEA is more reasonable, and compared with the FCE method, AHP-DEA is more objective and reduces the chance of result. By comparing the results of AHP-DEA and FSC, we can see that the results of the 12th and 15th ships are inconsistent The 12th ship should belong to a low-risk ship for the same reason as the 20th ship. This shows that the classification of AHP-DEA is more reasonable. By comparing the results of AHP-DEA with the Tokyo memo NIR, we can see that the results of the third and the 14th ships are inconsistent, They all had accidents and were punished by the administration, and therefore should not belong to low-risk ships, This shows that the classification of AHP-DEA is more reasonable. Furthermore, AHP-DEA can also rank ships according to the size of $\theta_{j}$, indicating its superiority.

\section{Discussion and conclusion}

In this paper, AHP-DEA method is adopted to propose a new ship- targeting model for ship 
site supervision, and some improvements are made to the unsuitable models of ship selection in the integrated AHP and DEA methods. The method not only reflects the preference of decision-makers, but also does not depend too much on the subjective judgment of decision-makers. It does not need to establish the relationship between production functions of input and output indicators, or repeatedly evaluate the weight of indicators, reduce the workload, and it has simple steps and convenient calculation. Compared with the traditional FCE method, FSC, NIR, it has strong effectiveness and superiority. The method can meet the requirements of vessel supervision and selecting a ship, and can not only prioritize the vessel supervision, but also classify the ship according to the degree of risk and have certain practical value for vessel supervision and selecting a ship.

\section{Acknowledgements}

This paper is supported in part by EU Horizons 2020 project (Grant No.690713)、National Natural Science Foundation of China (Grant No. 51408321)、Zhejiang Provincial Natural Science Foundation of China (Grant No. LY15E080013). and Ningbo Natural Fund Project(Grant No. 2016A610233)

\section{References}

[1] Ministry of Transport of the People's Republic of China. <The People 's Republic of China Ship Safety Supervision Rules>[Z]. 2017-07-01. (In Chinese).

[2] Li Zhenglian. Port State Surveillance System [D]. Dalian Maritime University, 2008. (In Chinese)

[3] Chen Lei, Wang Guangyu. Chinese national non-international ship safety screening mechanism selection [J]. China Marine, 2009, (03): 42-46. (In Chinese)

[4] Maria Hanninen, Pentti Kujala. Bayesian network modeling of Port State Control in inspection findings and ship accident involvement[J]. Expert Systems with Applications. 2014,03(7):62-74.

[5] Wei Dong and so on. Study on PSC inspection and selection model based on neural network [J] .China Oceanography, 2010, (8): 43-46. (In Chinese)

[6] Sun Zhonghua. Study on a new model of seaport state monitoring and selecting ship [J]. China Maritime Safety, 2012,12 (4): 71-75. (In Chinese)

[7] Sun Wei. Formulate a Scientific Mechanism for Selecting Ports and Improve Port State Surveillance [J]. China Water Transportation, 2010.05: 34-35. (In Chinese)

[8] Xie Haoliang, Jin Zhiwei, Wu Zhikui.Analysis of Internal Control Evaluation of Commercial Banks Based on AHP [J] .Chinese Annuity, 2013, (6): 75-76. (In Chinese)

[9] Liu Shun, Du Shuxin.Fuzzy comprehensive evaluation based on data envelopment analysis [J] .New Systems, 2010,24 (3): 93-98. (In Chinese)

[10] Lin Jikeng, Jiang Yuemei.An efficient scheme evaluation of black start in power system based on DEA / AHP model [J] .Automation of Electric Power Systems, 2007, 31 (15): 65-69. (In Chinese) 
[11] Xu Lin, Guo Yatao, Li Jidong. Research on risk assessment of micro-loan companies based on AHP-DEA model [J] .Journal of Rural Finance, 2007, (3): 31-34. (In Chinese)

[12] Zhou Fangtao.Ecological Evaluation of Regional Science and Technology Talents Based on AHP-DEA Method [J]. Chinese Journal of Management Science, 2013,27 (1): 8-13. (In Chinese)

[13] Zhang Shichang, Zhou Weijie.An AHP-DEA Model for Comprehensive Evaluation of Supply Chain Competence [J]. Value Engineering, 2008,07: 70-73. (In Chinese)

[14] V. Rezaie, T. Ahmad, N. Maan. Ranking the Multiple Intelligences of People with Epilepsy Using Analytical Hierarchy Process and Data Envelopment Analysis[J]. Journal of Emerging Technologies in Web Intelligence,2013,5(2):98-106.

[15] Y. Kasap, S. Kırı. An AHP-DEA Approach for Evaluating Electricity Generation Firms of OECD Countries[J]. Energy Sources,2013,8:200-208.

[16] Shang Yu-xin, Gao Ming-chen.Application of Analytic Hierarchy Process in Training Evaluation of China's Power Enterprises [J]. Economic Perspective, 2011, 07: 21-22. 